\title{
経肺熱希釈法の容量指標をもとに全身管理を行った卵巣過剩 刺激症候群の一例
}

\begin{tabular}{|c|c|c|}
\hline 統子 & 上原 & 健司 \\
\hline 後藤 隆司 & 鷹取 & 誠 \\
\hline
\end{tabular}

\begin{abstract}
要約：卵巣過剩刺激症候群 (ovarian hyperstimulation syndrome, OHSS) は排卵誘発薬により 血管透過性立進をきたす医原性疾患である。OHSSに対し血管透過性を定量的に評価した報告 はなく，今回，連続心拍出量測定装置 $\mathrm{PiCCO}^{\circledR}$ (Pulsion Medical Systems, Germany)を用いて 評価したので報告する。症例は30歳, 女性。不妊治療により妊娠し OHSSにて加療中, 胸腹 水が増加し入院 11 日目に心肺停止となった。蘇生後, 高PEEPを併用した人工呼吸管理を開 始した。ICU入室時, 肺血管外水分量係数 $24.8 \mathrm{ml} / \mathrm{kg}$, 肺血管透過性係数 5.8 と著明に増加し ていた。呼吸・水分管理を行い, $\mathrm{PiCCO}{ }^{\circledR}$ 測定值の正常化とともに呼吸状態は改善し，入室 4

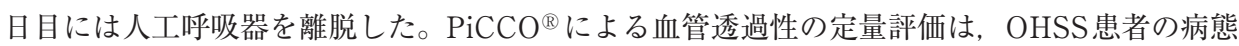
理解に有用と考えられた。
\end{abstract}

Key words: (1) ovarian hyperstimulation syndrome (OHSS), (2) $\mathrm{PiCCO}^{\circledR}$, (3)pulmonary vascular permeability index (PVPI)

\section{はじめに}

卵巣過剩刺激症候群 (ovarian hyperstimulation syndrome, OHSS) は排卵誘発薬により血管透過性立 進をきたし, 胸腹水貯留, 血栓塞栓症, 急性呼吸促迫 症候群，肺水腫など様々な症状を呈する疾患である。 肺水腫の原因として圧光進型か, 透過性光進型かを鑑 別することは，病態把握や治療方針を決定する上でも 重要と考えられる。しかし，OHSSに対し血管透過性 立進を定量的に評価した報告はない。今回，重症 OHSS 患者に連続心拍出量測定装置 $\mathrm{PiCCO}^{\circledR}(\mathrm{Pulsion}$ Medical Systems, Germany) を用いて, 肺血管外水分 量係数 (extravascular lung water index, EVLWI), 肺血管透過性係数 (pulmonary vascular permeability index, PVPI), 胸腔内血液容量係数 (intrathoracic blood volume index, ITBVI) などの定量的評価を行 い，良好に管理できたので報告する。

\section{症 例}

症例：30歳, 女性。
既往歴・家族歴：特記なし。

現病歴：不妊治療 〔human menopausal gonadotropin-human chorionic gonadotropin (hMG-hCG) 療 法]中に妊娠したが, 卵巣腫大と胸腹水貯留 (Fig. 1) にてOHSS と診断され入院となった。

入院後経過 : 胸腔・腹腔穿刺による胸腹水除去, 補 液などの対症療法を行っていたが，第 11 病日（妊娠 5 週）に心肺停止となり, 蘇生, 気管挿管, 両側胸腔ドレ ナージ後ICU入室となった。

ICU入室時身体所見：身長 $153 \mathrm{~cm}$, 体重 $67 \mathrm{~kg}$ (OHSS 発症前より $17 \mathrm{~kg}$ 増加)。㨂管下で意識レベル は清明, 血圧 $80 / 45 \mathrm{mmHg}$ 〔塩酸ドパミン $9 \mu \mathrm{g} / \mathrm{kg}$ / $\min (\gamma)$ 投与下], 脈拍 $150 / \mathrm{min}, \mathrm{SpO}_{2} 83 \%$, 体温 $36.0^{\circ} \mathrm{C}$ 。

検查所見：動脈血ガス分析值では $\mathrm{F}_{\mathrm{I}} \mathrm{O}_{2} 1.0$ 下, $\mathrm{pH}$ 7.272, $\mathrm{PaCO}_{2} 42.9 \mathrm{mmHg}, \mathrm{PaO}_{2} 46.4 \mathrm{mmHg}, \mathrm{HCO}_{3}{ }^{-}$ $19.3 \mathrm{mmol} / l, \mathrm{BE}-8.1 \mathrm{mmol} / l, \mathrm{Na}^{+} 131.7 \mathrm{mmol} / l$, $\mathrm{K}^{+} 3.89 \mathrm{mmol} / l, \mathrm{Cl}^{-} 101.5 \mathrm{mmol} / l, \mathrm{Ca}^{2+} 1.058$ $\mathrm{mmol} / l$, 乳酸 $2.5 \mathrm{mmol} / l, \mathrm{Hb} 11.1 \mathrm{~g} / \mathrm{d} l$, Ht $37.7 \%$ で あり, $\mathrm{P} / \mathrm{F}$ 比 46 と著明な低酸素血症を認めた。胸部単 


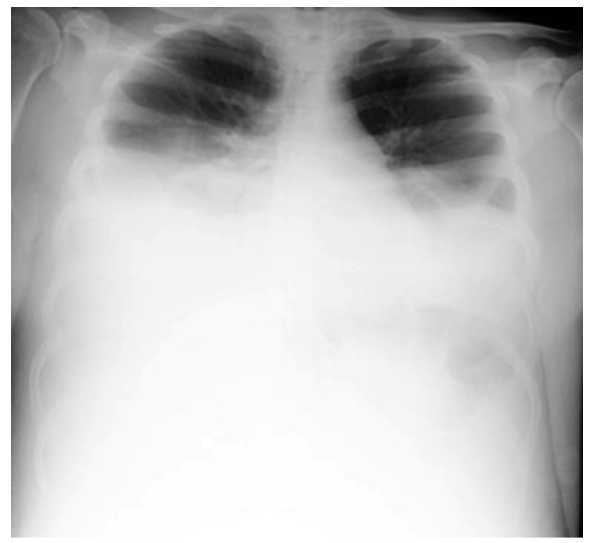

Fig. 1 Chest radiograph[on $\operatorname{admission}(\operatorname{day} 1)]$

純X線写真 (Fig. 2) では両側胸水, 肺門部栓血像を認 めた。経胸壁心臟エコーでは心収縮は良好であったが, 右心系の拡大を認め, 明らかな血栓や短絡血流は指摘 できなかった。下肢静脈エコーでは明らかな血栓は指 摘できなかった。腹部エコーでは両側卵巣が $72 \times 66$ $\mathrm{mm}, 136 \times 108 \mathrm{~mm}$ と腫大していた。

臨床経過：ICU入室時, 呼吸循環動態は不安定であ り，心肺停止・急性呼吸不全に至った病態の鑑別目的 に右内頸静脈から中心静脈カテーテル, 右大腿動脈か

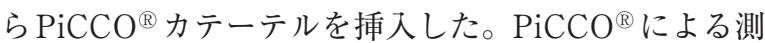
定の結果, PVPI (正常值 1.0 ～3.0) 5.8, EVLWI (正常 值 $3.0 \sim 7.0 \mathrm{ml} / \mathrm{kg}) 24.8 \mathrm{~m} l / \mathrm{kg}$ と著明に上昇してい たが, ITBVI (正常值850〜 1,000 $\mathrm{m} l / \mathrm{m}^{2}$ ) は771 $\mathrm{ml}$ $\mathrm{m}^{2}$ と軽度低值を示していた。心係数 (cardiac index, CI）は $4.05 \mathrm{l} / \mathrm{min} / \mathrm{m}^{2}$ と保たれていた。

病歴，画像所見， $\mathrm{PiCCO}^{\circledR}$ の結果より，OHSSまたは 胸水穿刺に伴う血管透過性元進型肺水腫と診断し, PEEP $20 \mathrm{~cm} \mathrm{H}_{2} \mathrm{O}$ を併用した人工呼吸管理を開始し た。肺血管透過性光進に対しヒドロコルチゾン 300 $\mathrm{mg}$ を静注した。高PEEPによる胸腔内圧上昇に伴い CVPは $19 \mathrm{mmHg}$ と非常に高值を示していた。

ICU 入室 24 時間後頃より次第に $\mathrm{P} / \mathrm{F}$ 比が改善し, こ れと並行してPEEPを下げることが可能となった。 ICU入室 36 時間後頃, PVPI 2.8, EVLWI $7 \mathrm{ml} / \mathrm{kg}$ と 低下し肺血管透過性光進は改善傾向を示した。しかし, 輸液負荷によりプラスバランスが続いているにもかか わらず, ITBVI $461 \mathrm{~m} l / \mathrm{m}^{2}$ と低下傾向で尿量も少なく 血管内容量不足と考えられた。これに対して, 尿量 0.5 $\sim 1 \mathrm{ml} / \mathrm{kg} / \mathrm{hr}$ 以上・Ht $38 \%$ 以下などを目標としなが ら5\%アルブミンを投与し, ITBVIを維持した。さら に塩酸ドパミン・ノルエピネフリン持続投与を行い血 行動態を維持した。血管内容量は不足していると判断 したため, 利尿薬は使用しなかった。その後, PEEP

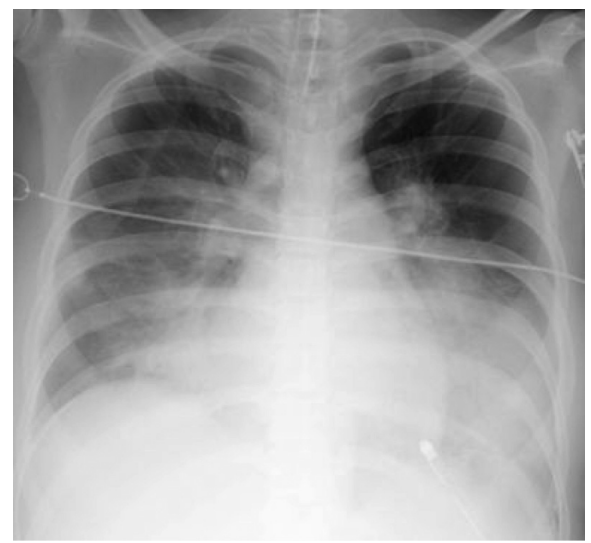

Fig. 2 Chest radiograph[after intubation (day 11)]

低下に伴い, 胸腔内圧の低下を反映してCVPは低下 しているが, ITBVIは徐々に増加し血管内容量の増加 を示していた。この時期より尿量も増加傾向を認めた。 入室時に挿入された左胸腔ドレーンからの胸水排液量 を補う速度で乳酸加リンゲル液と5\%アルブミンをほ ほ同量ずつ用いて補液し，尿量増加に伴い，水分出納 がマイナスバランスになるよう輸液管理を行った。

$\mathrm{PiCCO}^{\circledR}$ の值が正常範囲となることを目標に治療を 行い, 徐々に改善傾向を示し, ICU入室4日目には PVPI 2.2, EVLWI $6.2 \mathrm{~m} l / \mathrm{kg}$ まで低下, それに伴いP/ $\mathrm{F}$ 比も上昇し人工呼吸器から離脱した (Fig. 3)。塩酸 ドパミン・ノルアドレナリン持続投与は，陽圧呼吸か らの離脱や鎮静薬 (プロポフォール, デクスメデトミ ジン) 減量に伴い中止することができた。

徐々に胸水は減少し, ICU入室 16 日目に胸腔ドレー ンを抜去した。その後も呼吸状態は安定, 胸部単純 X 線写真でも改善を認めた (Fig. 4)。入室 27 日目の経胸 壁心臓エコーでは, 右心負荷所見は消失しており，末 梢性肺塞栓症を合併していた可能性が考えられた。出 産まで抗凝固療法を継続し, 妊娠 37 週, 帝王切開にて 母子ともに問題なく出産した。

\section{考 察}

OHSSは，過排卵刺激による卵巣腫大により，血管 作動性因子が産生・分泌され，血管透過性充進をきた す医原性疾患であり，1960年代初期にMullerらに よって報告された 1) 3)。血管透過性立進により様々 な症状を呈し, 本症例も胸水, 腹水, 体重増加, 血液濃 縮, 凝固障害などの症状を認め, Golan’s classification では重症に分類された3),4)。重症OHSS は排卵誘発患 者の $0.1 \sim 2.5 \%$ に認められる5)。本疾患は排卵誘発治 療でのゴナドトロピン投与量減量や, hCG 使用を避け るなどの一次予防が重要であり, 発症後の治療は水分 


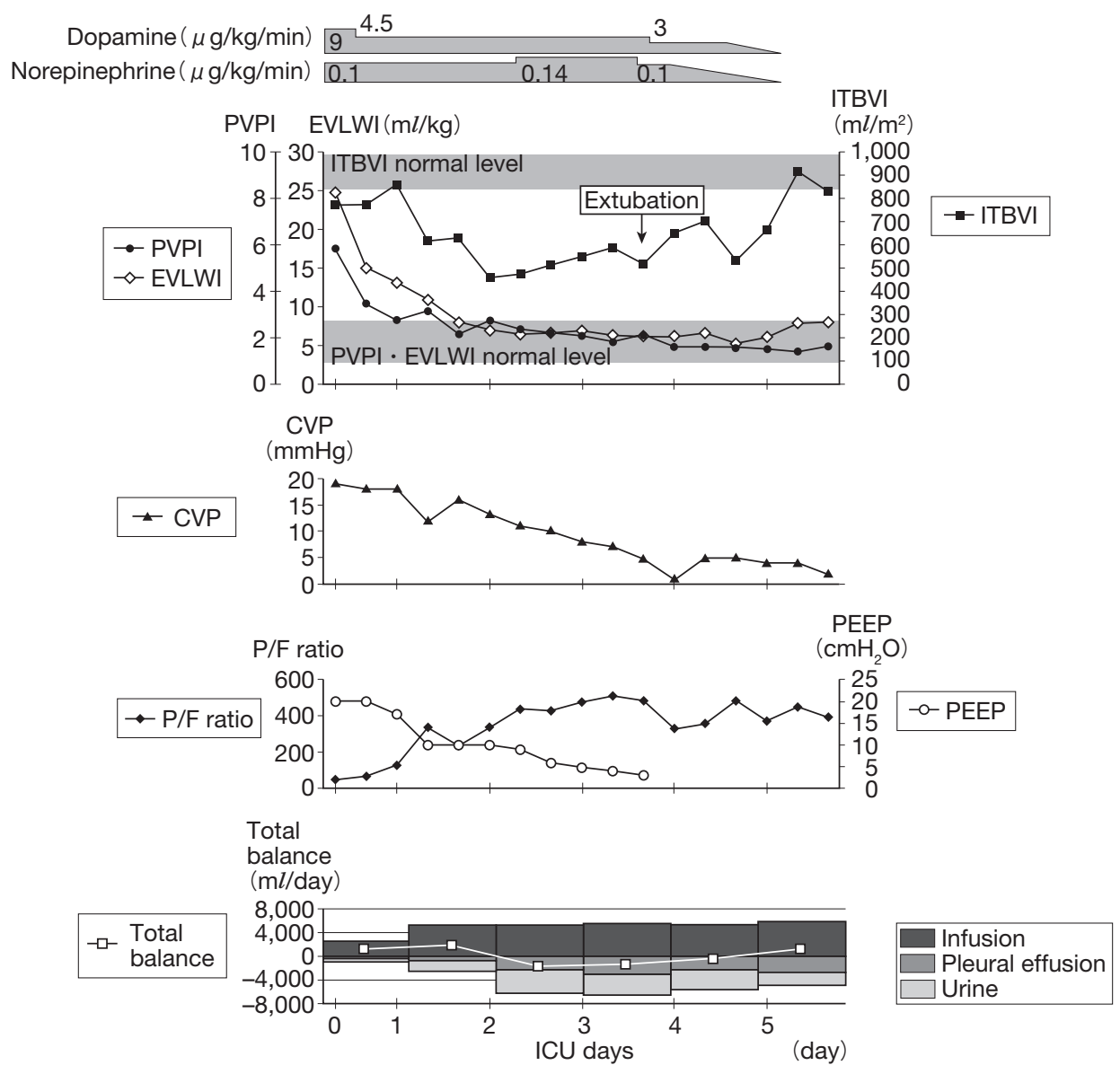

Fig. 3 Clinical course during ICU stay

EVLWI, extravascular lung water index; ITBVI, intrathoracic blood volume index; PVPI, pulmonary vascular permeability index.

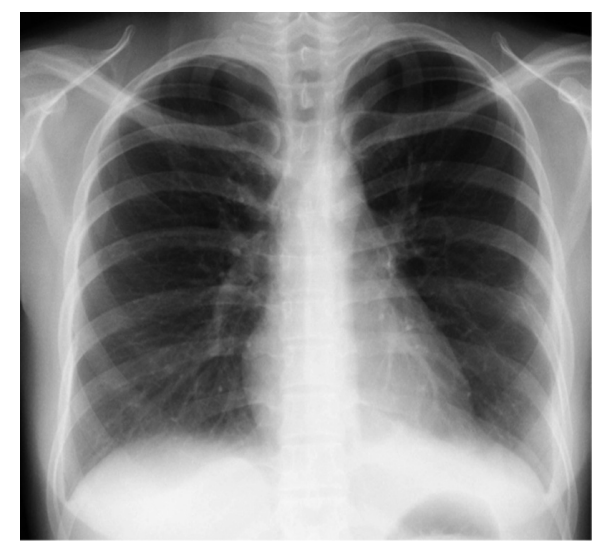

Fig. 4 Chest radiograph[before discharge (day 39)]

管理などの対症療法を行う 11 。通常 2 週間程度で軽快 するが，妊娠が成立している場合は遷延することも多 く, 人工妊娠中絶も治療選択肢の 1 つとなる ${ }^{3)}$ 。本症 例では, 妊娠 5 週と子宮内膜搔爬が困難だったこと, および, 本人の強い希望により行っていない。病態の 主体は血管透過性充進であるが, 本症例ではそれによ
り大量の胸腹水が貯留し, その後心肺停止に至ってい る。原因としては, 低酸素, 循環血液量減少, 肺梗塞 などが考えられた。心拍再開後は, 重度の呼吸不全に 至ったが, OHSSの血管透過性光進に伴う肺水腫, 胸 水穿刺に伴う再膨張性肺水腫の可能性が考えられた。

$\mathrm{PiCCO}^{\circledR}$ は, 日本では 2000 年に臨床使用に導入され た連続心拍出量測定装置である2),4),6)。中心静脈から 注入した泠水による温度変化を動脈内センサーで検知 し, Stewart-Hamilton 公式に基づいて心拍出量を測定 する4)。また, 動脈圧波形を解析し, この心拍出量に よる校正をもとに連続的に心拍出量を表示する。冷水 の到達時間と, 熱希釈曲線の解析によって 2 つ指標, すなわち胸胿内熱容積 (intrathoracic thermal volume, ITTV), 肺熱容積 (pulmonary thermal volume, PTV) を算出することができる6)。これらからITBVIや EVLWIが計算され求められる。具体的に本症例では, 右内頸静脈の中心静脈カテーテルから $0^{\circ} \mathrm{C}$ の冷水 10 $\mathrm{m} l$ を急速に注入し, 右大腿動脈から挿入している $\mathrm{PiCCO}^{\circledR}$ の動脈内センサーで測定している。EVLWI 
の信頼性においては, 剖検肺における肺重量と $\mathrm{PiCCO}^{\circledR}$ により求められる EVLWI との直線的な関係 が証明されている7),8)。また, ALI/ARDS (acute lung injury/acute respiratory distress syndrome) 鑑別に おけるPVPIの精度は高く cut off值として $2.0 〜 2.2$ が妥当であると報告されている99。本症例でも, ICU 入室時, PVPI 5.8 と著明な上昇を認めていた。あわせ て, EVLWI $24.8 \mathrm{ml} / \mathrm{kg}$ と著明に上昇しており血管透 過性が立進していること，またITBVIは軽度低值で推 移しており血管内容量は増加していないことを示して いた。CIは正常範囲内であり心原性肺水腫は否定的 だった。これらの所見より, 透過性立進型の肺水腫と 考えられた。人工呼吸, 水分管理などの対症療法によ り PVPI, EVLWIは低下し, 透過性立進の改善ととも に酸素化の改善, 病態の改善を認めた。

OHSSでは本症例のように透過性光進型肺水腫を合 併することがある。肺水腫治療としては水分管理が重 要であり, 肺動脈カテーテル (pulmonary artery catheter, PAC) を挿入し OHSSを管理した症例報告で は，2症例とも肺毛細管楔入圧 (pulmonary capillary wedge pressure, PCWP)の低下とともに酸素化の改 善を認めたと有用性を報告している10),11)。 $\mathrm{PiCCO}^{\circledR}$ と $\mathrm{PAC}$ を比較すると, 圧測定に関しては $\mathrm{PiCCO}^{\circledR}$ では CVP, PACではCVPに加え, 肺動脈圧・PCWPを測 定できる。心拍出量は両者において測定可能である。 しかし, PACではEVLWIやITBVIなどの容量評価, PVPIなどの血管透過性定量評価を行うことはできな い。肺血管外水分量の測定は $\mathrm{PiCCO}^{\circledR}$ をはじめとする 経肺熱希釈法を用いた循環モニターでのみ可能であ る ${ }^{4), 6)}$ 。CVPは本症例のように高PEEPを併用した人 工呼吸管理を必要とする症例では, 心房の経壁圧や血 管内容量を反映しない。同様に, PEEP減少に伴う静 脈還流の増加時には, 心蔵前負荷としての経壁圧は上 昇するが, CVPは見かけ上低下する。そのため, CVP から血管内容量の変化を定量的に把握することや, CVPのみを指標とした水分管理を行うことは困難で ある。本症例でも, ITBVIはこの血管内容量変化を適 確に反映し, 病態に応じた輸液管理を行うために有用 であった。ITBVIはCVP・PCWP と比較して左室前 負荷の指標として優れており，心臓前負荷指標には定 量的な容量測定の方が望ましいと報告されている12)。

$\mathrm{PiCCO}^{\circledR}$ を用いて, EVLWI・ITBVIなどの容量評 価, PVPIなどの血管透過性評価を行うことは, OHSS
の病態理解に有用であると考えられた。

\section{結 語}

今回我々は，心肺停止を合併した重症OHSSを経験 した。 $\mathrm{PiCCO}^{\circledR}$ はOHSS 発症時の血管透過性の評価に 有用であった。これまでOHSS患者に $\mathrm{PiCCO}^{\circledR}$ を用い て評価した報告はなく, 病態理解・呼吸循環管理に有 用と考えられた。

本論文の要旨は, 第39回日本集中治療医学会学術集会 (2012年, 千葉)にて発表した。

本稿の全ての著者には規定されたCOIはない。

\section{文 献}

1) 原田 省, 寺川直樹. OHSSの発生原因とその管理. 日産 婦会誌 1998;50:N135-8.

2) Zivi E, Simon A, Laufer N. Ovarian hyperstitmulation syndrome: definition, incidence, and classification. Semin Reprod Med 2010;28:441-7.

3) Whelan JG 3rd, Vlahos NF. The ovarian hyperstimulation syndrome. Fertil Steril 2000;73:883-96.

4) 杉村朋子, 村井 映, 益崎隆雄, 他. $\mathrm{PiCCO}^{\circledR}$ による肺血 管外水分量を指標とした体液管理で治療したacute respiratory distress syndrome(ARDS)の1例. 日集中医誌 2011;18:381-5

5) Sansone P, Aurilio C, Pace MC, et al. Intensive care treatment of ovarian hyperstimulation syndrome (OHSS). Ann N Y Acad Sci 2011;1221:109-18.

6) 田上 隆. 経肺熱希釈法で測定される肺血管外水分量と肺 血管透過性係数：輸液管理の新たな指標. 日臨麻会誌 2011;31:353-8.

7) Tagami T, Kushimoto S, Yamamoto Y, et al. Validation of extravascular lung water measurement by single transpulmonary thermodilution: human autopsy study. Crit Care 2010;14:R162.

8) Kirov MY, Kuzkov VV, Kuklin VN, et al. Extravascular lung water assessed by transpulmonary single thermodilution and postmortem gravimetry in sheep. Crit Care 2004;8:R451-8.

9) 久志本成樹, 平 泰彦, 北澤康秀, 他. 急性肺水腫の定量 的評価による病態解析に関する多施設共同前向き試験：中 間解析結果. 日集中医誌 2011;18:253-7.

10) Zosmer A, Katz Z, Lancet M, et al. Adult respiratory distress syndrome complicating ovarian hyperstimulation syndrome. Fertil Steril 1987;47:524-6.

11) BaHammam AS. Pulmonary edema complicating ovarian hyperstimulation syndrome: low-pressure edema, highpressure edema, or mixed edema? Ann Saudi Med 2005:25:335-8.

12) Lichtwarck-Aschoff M, Zeravik J, Pfeiffer UJ. Intrathoracic blood volume accurately reflects circulatory volume status in critically ill patients with mechanical ventilation. Intensive Care Med 1992;18:142-7. 


\title{
Abstract \\ A case of ovarian hyperstimulation syndrome in which transpulmonary thermodilution technique monitoring was used
}

\author{
Noriko Terada, Kenji Uehara, Yuko Tanabe, Takashi Goto, Makoto Takatori, Keiichi Tada \\ Department of Anesthesia, Hiroshima City Hospital
}

7-33 Motomachi, Naka-ku, Hiroshima, Hiroshima 730-8518, Japan

Ovarian hyperstimulation syndrome (OHSS) is an iatrogenic complication of controlled ovarian stimulation, and its main pathophysiology is increase of capillary permeability, especially in the lungs. There has been no reported case of OHSS documented by quantitative evaluation of vascular permeability. Here we report a case of OHSS in which we used $\mathrm{PiCCO}^{\circledR}$ (Pulsion Medical Systems, Germany) to obtain numerical data for the clinical course of the pathophysiological status. A 30-year-old pregnant female developed OHSS after infertility treatment and was admitted to our hospital due to increased pleural effusion and ascites. On the 11th hospital day, she fell into cardiac arrest and was transferred to the ICU after successful resuscitation. She needed $20 \mathrm{cmH}_{2} \mathrm{O}$ of PEEP for maintenance of appropriate oxygenation on a mechanical ventilator. An initial examination using a PiCCO ${ }^{\circledR}$ catheter showed that the extravascular lung water index (EVLWI) was $24.8 \mathrm{ml} / \mathrm{kg}$ and pulmonary vascular permeability index (PVPI) was 5.8. After vigorous body fluid and respiratory management, EVLWI and PVPI decreased to $6.2 \mathrm{ml} / \mathrm{kg}$ and 2.2 , respectively, on the 4 th ICU day. She was successfully weaned from the mechanical ventilation and delivered a baby by cesarean section. Both the mother and child are doing well. PiCCO ${ }^{\circledR}$ monitoring provides useful quantitative information in evaluating the clinical condition of OHSS.

Key words: (1) ovarian hyperstimulation syndrome (OHSS), (2) $\mathrm{PiCCO}^{\circledR}$, (3) pulmonary vascular permeability index (PVPI)

J Jpn Soc Intensive Care Med 2014;21:29-33. 